\title{
La interculturalidad cooperativa en Euskadi: la perspectiva pública
}

\author{
Alfredo Ispizua Zuazúa \\ Gobierno Vasco
}

\section{Multiculturalidad, interculturalidad y cultura}

1. El uso frecuente, en ámbitos diversos, de los términos: multiculturalidad, interculturalidad e incluso "transculturalidad», por los problemas de polisemia que derivan, exige un esfuerzo previo de aproximación válida a su concepto y significado a los efectos, al menos, de lo que se expone a continuación.

Ya en 1995 se preguntaba Alain Touraine «qué es el multiculturalismo» y explicitaba su preocupación (que requiere un esfuerzo reflexivo e investigador previo) por lo que en realidad significa el término (entonces no tan abierto o que hubiere dado lugar a otros), su sentido real y además compartido —estar de acuerdo en lo que significa o, al menos, no significa- ${ }^{1}$.

$Y$ es que efectivamente, se ha de ser especialmente cuidadoso con las palabras, pues éstas tienen un sentido que puede no ser compartido.

2. Una segunda advertencia es, asimismo, precisa en cuanto a la forma de abordarlo.

En efecto, aquí no se pretende una comprensión de todos los elementos de la interculturalidad, todos sus sentidos y sus derivaciones y sí la comprensión funcional de aquellos elementos de la interculturua-

1 www.campus-oei.org/cult002.htm.

Identifica cuatro significados parciales:

- Defensa de las minorías y sus derechos.

- No inmiscuirse en mis diferencias culturales, intactas.

- Simple tolerancia de otras culturas

- Rechazo a la cultura occidental. 
lidad relacionados con el cooperativismo. Esto es, una parte del todo complejo.

3. La multiculturalidad hace referencia básicamente, al reconocimiento de la diversidad, a la alteridad (al otro) pero:

- Constreñido a la convivencia o coexistencia de entidades (de unidades) aisladas entre sí, con autonomía.

— Una aplicación de la ética liberal-individualista, al grupo.

De manera que se trata de una forma de organización del grupo de su diversidad interna.

4. La interculturalidad nos sitúa en cambio, en el ámbito del encuentro, del entendimiento muto entre culturas diversas, lo que exige a su vez, entre otras cuestiones:

- La armonización de los intereses y relaciones.

- Poner en común, compartiendo.

- Horizontalidad de la relación intercultural (no dominación).

- Una ética liberal-humanista.

— La relación actuación local-pensamiento universal.

Sobre todo, diría a los efectos que interesan singularmente en este contexto, que la interculturalidad más que la suma de individualidades autónomas busca lo común de entre ellas.

5. Por otra parte, por Cultura podemos entender, haciendo abstracción de los múltiples enfoques con que puede ser abordado:

— Un sistema de creencias y valores compartidos.

- Un conjunto de conductas utilizadas en la organización de procesos sociales; que es en realidad, el camino-pautas, principios rectores, para traducir los valores generales en objetivos concretos.

Entendemos que resulta razonable afirmar, desde la óptica funcional que tratamos este análisis, que la cultura es parte del todo social: lo económico-social también es cultural e incluso, más concretamente, puede trasladarse al ámbito organizativo.

Esto es, lo mismo que los pueblos desarrollan una determinada cultura al intentar dar respuesta a los problemas sociales, económi- 
cos y políticos («abrirse paso juntos, entre problemas y contrastes, a lo largo del tiempo», GREENWOOD), otras unidades convivenciales, otras «comunidades» por ejemplo organizaciones empresariales construyen ideas descriptivas y normativas:

- Cómo funcionan las cosas, el mundo.

- Cómo debe ser la conducta de sus miembros y de los demás.

Este contexto que permite describir y normar adoptando soluciones, criterios, podemos denominar CULTURA. Seguimos así el planteamiento metodológico conceptual utilizado por WILLIAM FOOTE WHYTE y KATHLEEN KING WHYTE al analizar las Cooperativas de Mondragón².

De hecho, se habla ya con cierta «normalidad» de «cultura corporativa» aplicada al ámbito empresarial, como «marca» (aspecto comercial, aunque no sólo) de la entidad que identifica una forma de hacer y relacionarse con trabajadores, clientes (con todos los stakeholders para utilizar otro término en boga: todos los que tienen algún interés en la empresa ${ }^{3}$.

Desde esta perspectiva, la cultura «sirve» para dar consistencia a la identidad empresarial, la cultura corporativa «une» (las diferencias y a los diferentes) y da «identidad», además de «estabilidad».

Pero, consistencia y estabilidad no significan inmovilidad, petrificación. En efecto, si la cultura es la forma de comprender el mundo (definición antropológica) a medida que este cambia y lo hace mucho y cada vez más de prisa, la forma de interpretar también se adapta aunque lo hace desde criterios o posiciones claras y permanentes (Valores de la $\mathrm{ACl}$ ). Ejemplo: valor: democracia; principio: un hombre, un voto.

\section{Aplicado al cooperativismo}

6. El cooperativismo reconoce y respeta la individualidad como base de su sistema organizativo y valora (tiene en cuenta; no solo lo

2 William Foote WhYTE y Kathleen KIng WHYTE: Mondragón: más que una utopía. Editorial Txertoa, Donostia, 1988.

3 Greenwood, Davydd y González, José Luis: «Culturas de Fagor», Estudio antropológico de las cooperativas de Mondragón, E. Txertoa, Donostia, 1989. 
oye) los aportes de cada individualidad, su interpretación de la realidad empresarial y social cooperativa.

Pero no que queda ahí; como valora la diversidad, considera la misma como valor sobre el que construye, crea, se desarrolla identificando lo común (diría que es lo propio de la organización y de la filosofía cooperativa).

E incluso cuando ya no se tratara de crear sino aún de no destruir, con la simple constatación de diferencias y su respeto no resuelve los conflictos y parece que estos hay que resolverlos cuando aparecen en el seno de una organización (empresa cooperativa) o en un sistema (cooperativismo).

Puede objetarse quizá, que lo que se acaba de decir es predicable de toda cultura corporativa, sea cooperativa o no. Pero, lo que desde luego no puede afirmase de todos los casos es que la cultura corporativa se fomente y forme democráticamente, desde la base, cooperativamente. Una cosa es que se estimule desde la propiedad y gestión empresarial la cultura corporativa por los efectos positivos que derivan del mismo y otra que se construya democráticamente por los propios protagonistas del proyecto empresarial: los socios trabajadores. Los procesos institucionales son democráticos en las cooperativas ${ }^{4}$.

Por ejemplo, en caso de «Las culturas de Fagor» el estudio trata de identificar «la cantidad de heterogeneidad (multiculturalidad) que el sistema (cooperativo de Fagor concretamente en este caso) es capaz de asumir y gestionar sin desintegrar su identidad. O dicho de otro modo, la forma de equilibrar en el tiempo valores compartidos y experiencias vitales diferenciadas».

4 «En la empresa privada los directivos tienden a dar por supuesto que comprenden esa cultura por el mero hecho de que conocen en términos generales la empresa privada a partir de su propia experiencia, de lo que han aprendido de amigos y familiares y de lo que leen. Sin embargo, para forjar nuevas relaciones entre los trabajadores y la dirección, los dirigentes de la empresa privada tendrán que reflexionar y debatir sobre la cultura que desean construir para su organización.

Al diseñar y dar forma a una cooperativa de trabajadores o a una empresa en que su propiedad corresponda a sus empleados, entidades sobre las que no hay conocimiento ni experiencia generalizadas, los dirigentes han de pensar desde el principio en la construcción de una cultura organizativa y en examinar y replantear esa cultura a medida que cambien las condiciones. (...) No puede crearse una cultura organizativa por decreto (...) ni consiste en lo escrito y difundido, sino en su aplicación práctica día a día, en los concretos comportamientos - teoría en uso-teoría adoptada-. Foot y KING: «Mondragón: más que una utopía», citado, p. 337. 
Y esto no sólo es predicable de Fagor sino, en esencia, entiendo que de toda cooperativa, que está en su ADN, en su propia razón de ser — cómo se organiza - y en el sistema axiológico del cooperativismo (más allá de la cooperativa como empresa).

7. Así, son expresiones de respeto de la diversidad pues no tiene porque haber total uniformidad:

— El desarrollo personal —individualizado en función de sus actitudes y aptitudes - como resultado y consecuencia del trabajo cooperativizado.

- Garantizar a sus miembros voz y representación: la accesibilidad de todos los miembros y por lo tanto, de todas las opiniones, conflictos, etc., a las estructuras de gobierno.

- La Auto-ayuda.

- El Pluralismo democrático es una situación multicultural; esto es, el reconocimiento del derecho del otro a la conformación de la decisión orgánica en igualdad de condiciones en principio (no por el valor económico aportado a la entidad). Guarda la libertad económica (de formas de hacer economía, de hacer empresa).

- Prohibición de discriminación por raza, lengua, sexo, religión, ideas.

8. Elementos que destacan lo común, la dimensión comunitaria, los servicios mutuales. Son expresiones de igualdad, de solidaridad:

- La comunidad de trabajo (cooperativas de trabajo asociado): reciprocidad de relaciones.

- El patrimonio común, patrimonio cooperativizado: compromiso con las generaciones futuras y con lo local.

- Los equilibrios de ponderación en la redistribución de beneficios.

\section{El cooperativismo (Economía solidaria y comunitaria) en su contribución a la interculturalidad (a la vez herramienta y resultado)}

9. La asunción real y efectiva de la interculturalidad modifica de hecho, o ha de hacerlo, concepciones o interpretaciones de nociones como la igualdad o la libertad, porque: 
1. Las cooperativas actúan en lo local: ámbito empresarial y social concreto: el lugar donde se asiente. Es lo que se ha denominado enraizamiento cooperativo.

Si bien, como consecuencia de la globalización de mercados la actuación sobrepasa lo local extendiéndose a ámbitos internacionales 5 .

2. Piensan globalmente porque su ideario es compartido internacionalmente entre culturas económicas y sociales diversas que están de acuerdo en lo esencial.

Además de la pretensión de integrar trabajadores de otras culturas: localizaciones internacionales de empresas de MCC: profesionales desplazados a otros lugares; integrar trabajadores de filiales de otros lugares.

El compromiso cooperativo es un compromiso compartido. Así, la Alianza Cooperativa Internacional fue fundada en Londres en 1895, agrupa 230 miembros, son organizaciones cooperativas nacionales e internacionales de todos los sectores de actividad y de 92 países. En total representan aproximadamente 800 millones de personas en todo el mundo

Como afirma la declaración centenaria de la $\mathrm{ACl}$ «las cooperativas de todo el mundo se han desarrollado en una rica colección de sistemas de creencias, incluidas todas las grandes religiones e ideologías del mundo» que han infuido en líderes y grupos cooperativos. Y efectivamente conseguir un consenso sobre valores entre las cooperativas a este nivel es una tarea realmente compleja aunque por lo mismo, gratificante ${ }^{6}$.

5 Se habla ya de «pensar global y actuar global». Primera reunión del Consejo para la Globalización, Sintra, Portugal, 10.11.06.

6 Valores: autoayuda, autorresponsabilidad, la democracia, la igualdad, la equidad y la solidaridad.

Principios: que son pautas de comportamiento y para la toma de decisiones, normas de conducta; criterios más que mandamientos rígidos:

- Adhesión voluntaria.

- Gestión democrática por los socios.

- Participación económica de los socios.

- Autonomía e independencia.

- Educación, formación e información.

- Cooperación entre cooperativas.

- Interés por la comunidad.

Principios cuya fuerza jurídica se adquiere en el caso vasco por el artículo 1 de la Ley de Cooperativas 4/1993, de 24 de junio, de Euskadi que dispone que las coopera- 
3. Se sostienen en una ética. Los socios fundadores hacen suyos los valores éticos de la honestidad, la transparencia, la responsabilidad y la vocación sociales.

Quisiera recalcar que las cooperativas están abiertas a cooperar con esas comunidades (socialmente reponsables).

4. Tiene una identidad propia (que no es exactamente la suma de identidades individuales).

Las cooperativas no desempeñarán un papel importante en el futuro si no utilizan su diferenciación (ACI) que consiste básicamente en la aplicación de procedimientos democráticos a actividades económicas que contribuyen al bienestar de todos.

\section{Ejemplos concretos de interculturalidad facilitados o potenciados desde el ámbito público}

10. También se producen elementos de interculturalidad (facilitándola) cuando se posibilitan espacios de relación entre cooperativas o, por mejor decir, entre movimientos cooperativos de ambitos geográficos diversos.

Cuando se institucionalizan relaciones de cooperación entre el movimiento cooperativo vasco y, por ejemplo, el argentino, el uruguayo o el de la República Dominicana para establecer lazos, intercambiar experiencias y proyectos y explorar posiblidades de complementación económico social.

11. Así, el cooperativismo, se ha dicho, es una escuela de democracia; aquí en este contexto, creo no excesivo afirmar que es también una escuela de interculturalidad en el sentido de que a través de él, los individuos y los grupos aprenden (aunque a veces sea por necesidad antes que por convencimiento) mutuamente de las prácticas concretas de hacer empresarial y social, respondiendo a una filosofía propiamente cooperativa de participación y no dominación.

Digo esto en el sentido de que se trata de superar una forma de pensar que se identifica bien en el viejo adagio de Horacio: Coelum

tivas deberán ajustar su estructura y funcionamiento a los principios cooperativos; recalcando la exposición de motivos «la plena fidelidad» de la regulación positiva vasca a los principios cooperativos proclamados por la $\mathrm{ACl}$. 
non animan mutant qui trans mare currunt, los que atraviesan los mares cambian el cielo sobre ellos, no su alma.

Y es que en efecto, la economía social se tiene aquí entre nosotros (incluso entre nosotros en Euskadi, donde tenemos como primer grupo empresarial un grupo cooperativo) sin atravesar mares, como la «otra» forma de hacer empresa, de economía; que intentamos impulsar desde lo público en «interculturalidad» con la forma ordinaria de hacer empresa. Cómo esta otra economía contribuye a resolver los problemas socio económicos locales y globales.

Interculturalidad practicada día a día, en los distintos espacios donde se encuentran ambas dos; de diálogo permanente.

12. Que es el que también traemos aquí al ámbito universitario mediante jornadas como esta: un diálogo permanente y abierto sobre la economía social y sus múltiples facetas (convergencias y divergencias culturales), en el que ganaremos todos, sobre todo la economía social vasca. 